\title{
A Development of Expert design system for DRAW DIE in Automotive industry
}

Tae-Soo Kim, Soon-Kyu Lim and Sang-Jun Lee

CAD/CAM Research Center,

Korea Institute of Science and Technology,

P.O.BOX 131, Cheongryang, Seoul 130-650, Korea

TEL: +82-2-958-5645 FAX: +82-2-958-5609

E-mail: ktaesoo@kistmail.kist.re.kr

\begin{abstract}
This paper presents the research on the development of expert design system as a 3D CAD customising systems for the draw die in automotive industry. This system support the die design efficiently and systematically by utilizing standard data, design knowledge. The standard data and design knowledge of draw die has been accumulated through interview with design experts of Motor Company in Korea. This paper describes a methodology for systematic die design, automatic checking of dimensions and how to implement it. The expert design system is being developed on the basis of product data. All components of die are regarded as product data and system takes the component as the unit of die. . Parametric design using knowledge base and standard database is introduced for easily deal with various and complicated design knowledge. For implementation, this expert system is programmed by $\mathrm{C}$ and Motif. And system can be used linked with CATIA.
\end{abstract}

\section{Keywords}

Draw Die, Press, Expert system, Knowledge-base, Parametric design, Standardization, Product data 


\section{INTRODUCTION}

The Die is essential tool to make the panel for an automobile and its cost, quality, delivery date and safety is determined in design process. In press operations, in accordance with roles, Die can be grouped as drawing dies, trim dies, Blanking and piercing dies and Progressive dies. The draw dies are designed to forced the flat blank through an opening or into a cavity of the required shape, and at the same time so confine the metal between the drawing surfaces that the change in form from a flat blank to the desired shapes, is accomplished without excessive wrinkling or other defects.

In automotive industries, draw die design for press process is complicated and time-consuming process. And experience of designer is the main tool in this process. But, It is more common practice to design by trial and error method, rather than by engineers who have experiences due to lack of experienced engineers in this field.

The most of commercial CAD system has been in the scope of geometric representation of the object till now. Recently, some works on knowledge based design have been reported.

The object of this research is the development of the Knowledge-based CAD system for Draw die, which can support efficiently and systematically whole procedure of draw die. The expert design system consists of Standard database, Knowledge base, design process control module and geometric modeler (CATIA). The CATIA is used as the overall CAD environment and Knowledge base is consisted of selected design rules and design process which is gathered from experts and standardized. They are programmed by $\mathrm{C}$ language. To reduce design man-hour, human errors and the deviation which depends on designer's skill, a Knowledge-base and Standard database is used to automate the design process and evaluation of the geometry. And it also used to determine the design variables; components' type, size, layout position, and their relation. Therefore, repetitive engineering calculation, evaluation of the 3-D geometry can be automatically done by the system. And with this system, draw die can be designed by minimal user input. This development is based on the parametric design concept and uses: 1) construction of standard design process, 2) standardization of draw die components and construction of standard database 3) construction of knowledge base and decision making by knowledge .

\section{ANALYSES OF DRAW DIE DESIGN PROCESS}

\subsection{Present Design Method and Problem}

Die is essential tool to make the body panel for an automobile. Hence, the process plan and design for die play an important role. Because its cost, quality, delivery date and safety factor is determined in design step.

Die used in press process for an automobile consists of Draw die, Trim die, Flange die, Cam die, Blanking and piercing die and Progressive die. The Draw die 
process is to force the flat blank into a cavity of the required shape, and at the same time so confine the metal between the drawing surface that change in form from a flat blank to the desired shape. This process depends on the thickness of the metal, depth of the draw, and heights of the flange to be formed. Specification of the die to be used for a particular application must be governed by experience and a knowledge of the operation and construction of the various types. In past draw die designing cases, designer examines whether the panel geometry data has defects or not. If there are some defects, it should be rearranged. After this process, designer points out the punch profile and blank curve among the surfaces and curves which consist panel geometry. First step to be performed is to determine die face, offset line and design of wear plate, Block lifter and gauge. Next important step is determination of Die size and layout design of die set. Finally, several components, which compose of, die set such as balance block, cushion pin, rib, etc. are designed. Until now, Even if they were expert of commercial CAD system, this process is performed manually. Engineers used approximated work-piece sizes and tentative methods, and relied on past experiences to layout the die sets. And designs are proved to have errors because of the difficulties in reasoning 3D free surface of car body from 2D draft and complexity of rule, which determine various design variables.

\subsection{Design Process Improvement}

The basic ideas of this work are automation and systemisation of parametric design using knowledge base and standard database. In this paper, we established the design process of draw die based on the knowledge base and decrease possibility of error occurring in design step of draw die. The design know-hows of specialist and standard data are gathered from an interview with design engineers from Press engineering Department of $\mathrm{H}$ Motor Company.

As shown in Figure 1, The basic layout of draw die is decided by initial input such as 3-D panel geometry, die type, and specification and configuration of press machine. Panel geometry, out of the initial input, designer should point out the punch profile and black curve interactively. For this process, system automatically generate the 2-D geometry from the 3-D. At this point, punch profile, blank curve should meet the condition, 1) isolation, 2) $\mathrm{C} 1$ and $\mathrm{C} 2$ continuity, 3) closed curve. In real design, most of panel design data violates these conditions, and designer should modify the curve to meet these qualifications, and consumed a lot of time for this work. In our system, we developed the continuity function that completes the curve automatically. If that done, system calculate the areas of punch, blank by projection and translation automatically. Next, die layout and die size, corner heel, safety area, receptacle box are decided and designed from the initial input, standard component which standard database have. Die set is consisting of upper and lower die and they have mutual relation. So, our approach is that upper die and lower die is designed simultaneously. 


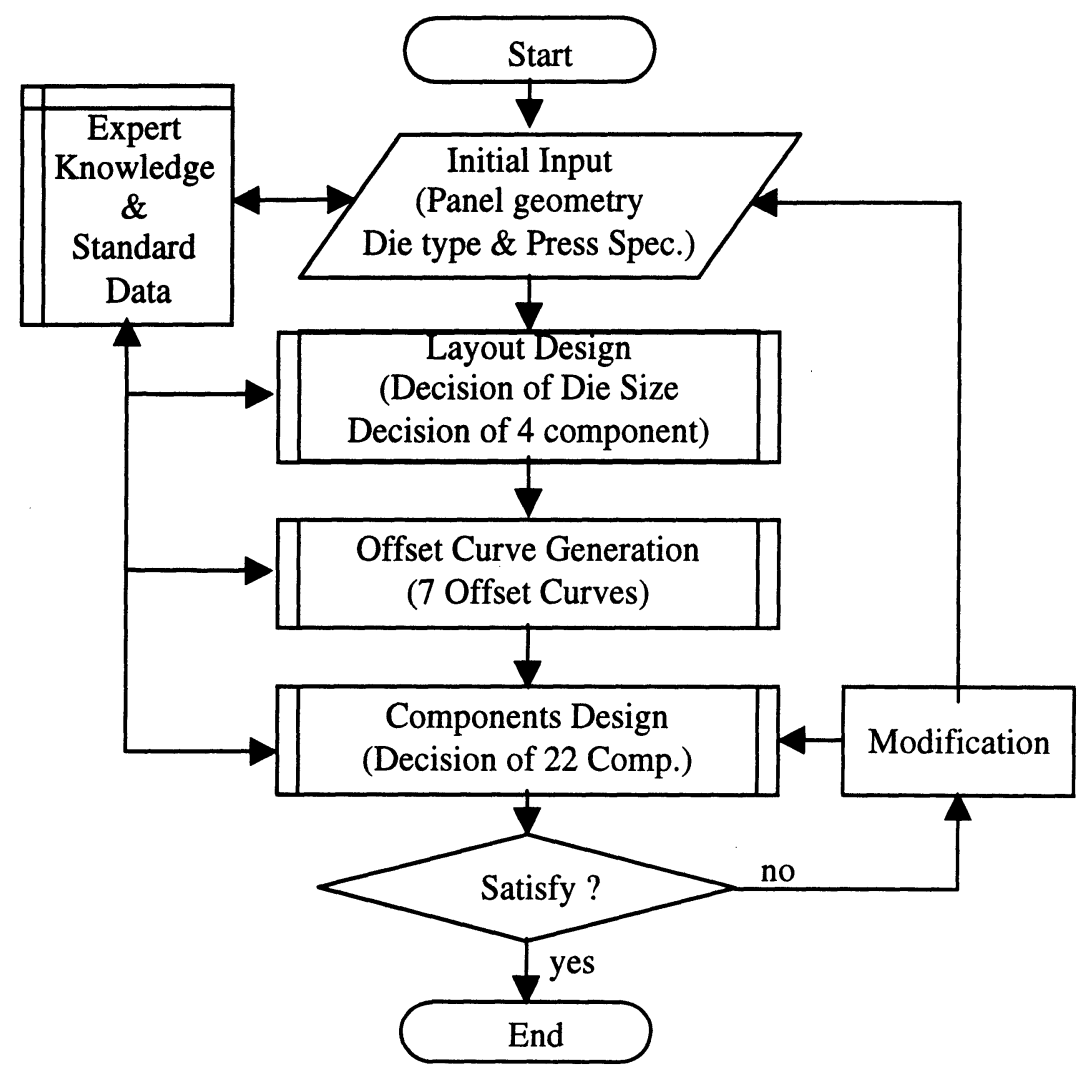

Figure 1 Design Process of Draw Die

This process is controlled by design process control module and design decision is controlled by the use of knowledge base of experience and accumulated know how. After this process satisfactory, System can generate the 7 offset curves which is required for draw die design. Next is components design step. In this research, we standardize the 26 components of a draw die. The kinds and number of components and dimensions are decided by the use of knowledge base also. In this step, System requires designer's decision for location. Because, positioning knowledge of some components can't decided the exact location of the component but only advice the ranges which component can be located.

If the result of design is not satisfactory, the design can be modified. And design is completed satisfactory; result of design can be used in next phases of designing or manufacturing.

During the design and its modification, reliability and efficiency of the result are ensured by the full use of knowledge base of experience and accumulated knowhow. 
Comparing with the manual method, this Expert System improves accuracy and saves time to calculate and evaluate complex geometry data of panel and relation between components

\section{EMBODIMENT OF EXPERT SYSTEM}

\subsection{Construction of Draw Die Design System}

This Expert system is composed with 5 Module. The User Interface Module which helps designer to communicate with system and design draw die easier and faster. The Design Process Module is the main module of this system and generates the design result by combination of design knowledge, database and input data. And it also control the data generated at a design step to store it and call it systematically. And the Rule-base Module which helps represent the design know-how of a design specialist and design rules of the automotive industry and Output Control Module would generated design result automatically, and Standard Database has Standard components, design output which is designed previous. It is shown as Figure 2.

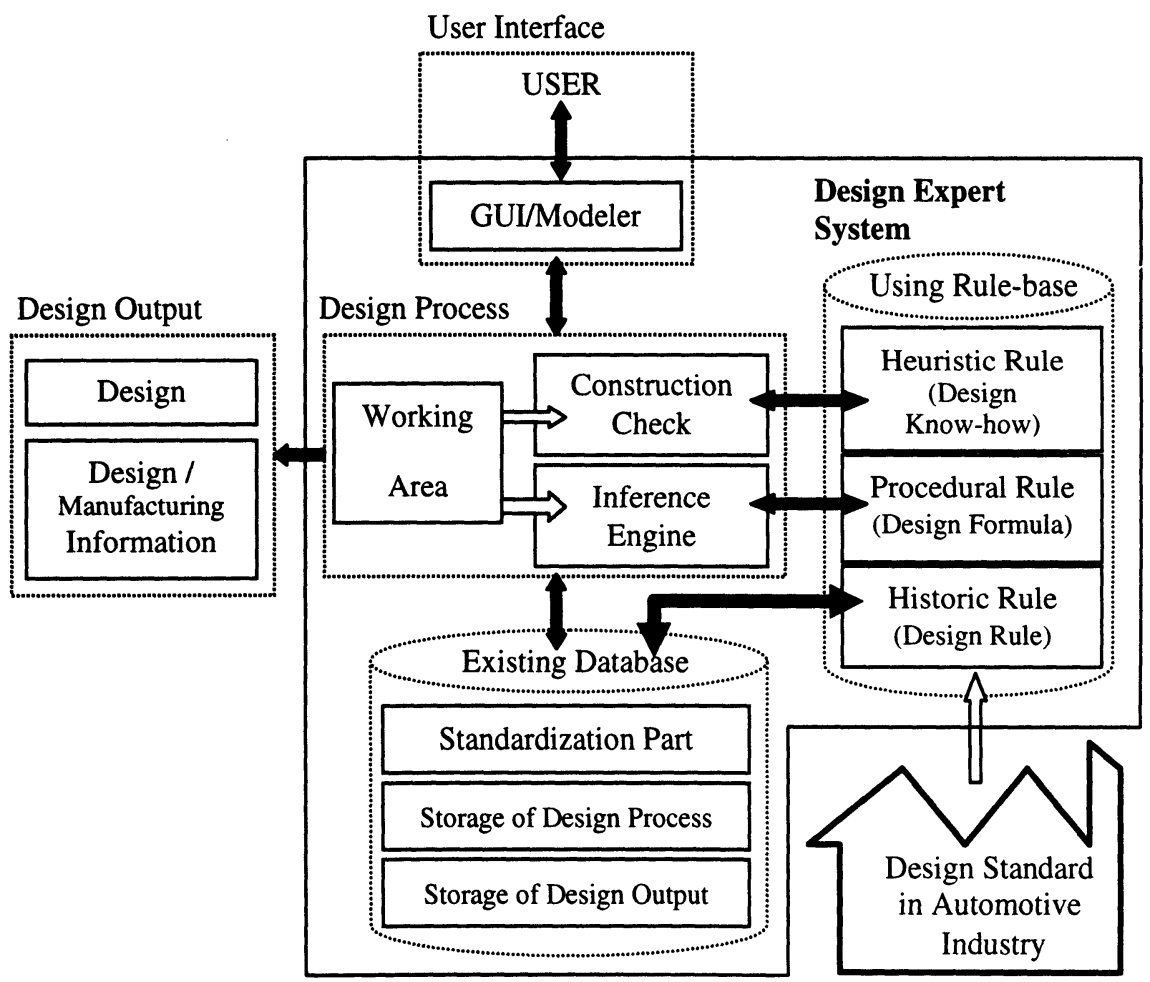

Figure 2 Construction of Draw Die Expert System 
So using this system enables design process to be dialogical one and estimate the design error due to user input in order to prevent a failed design. Hence, the system can be used as a design checking process and to infer the result of design.

\subsection{Representation of Design Rule}

When a panel that has prismatic shapes and complicated structures is designed, another design result is generated from appeared design condition's selection in user's design method and design process, also to prove error's causes is obscure when the design is faulty.

But, design method's varieties and shape's complicated structures have design methods and rules with uniformity and have repetitions in many cases.

Therefore, at present, owing to analyzing design process method that has various structures and complicated shapes of panel and abstracting a uniform design method and design rule with consistency form, manufacturers that design and produce a particular part is going on with standardization of design process.

In this study, owing to abstracting specialist's design know-how and design rule from design process, a design process is standardized and converting the design method and rule into a rule-base for Draw Die design. At this point, according to operation of a user in 2-dimensions, for the sake of semi-automatically assembling each block, the representation of design rule and that kind with standardization is defined as follow;

- Historic Rule ; Generalized Design knowledge and Design method $\rightarrow$ Feature of each component, Selection of Die Type, Component selection in die shape, Maximum / minimum gap of component in this die, Positioning dimension of each component, Number and designing position of each component, etc.

- Heuristic Rule ; Design method of design specialist and Design know-how $\rightarrow$ Location of each component in Draw die shape, Position decision factor, Machining margin, Method of component separating, Width margin, Structure of Joint component, etc.

- Procedure Rule ; Calculation tool of dimension by Design formulation and Design rule $\rightarrow$ Mutual relation between component's height and length, Separation length between each component, Calculation distence of component, etc.

Also, because a design rule is continuously changing and advancing, for changing and repairing the design process and design work standard, the design rule-input mode is appended.

Our system, according to accumulating and storing the specialist know-how and heuristic knowledge in relation with design, reduces dependence on users, and rapidly adapts to new design objects because of accumulating all rule bases with past design knowledge. 


\subsection{Draw Die Design Step}

The next step is to arrange the block using Grid line in 2D by design rules as mentioned before, and to use rule-base data management method in order to decide the Draw die Type by Die size and car's body panel shape to be formed in arranged die shape.

There are four major functions in draw die design system. These are selection of components and it's dimension and shapes from standard database, determination of layout position, construction of the relations among the components and geometries, and modification of the parts and die size which is designed previously. This programs covers four different types of draw dies; three single action type (transfer, tandem, and cross bar) and one double action type.

User must decide shape check interval of draw die in product surface feature before deciding height of components feature, divide surface shape and height of draw die to decided check interval. So can decide positioning of each components by this divided point and an intersecting point on 2-dimensional die shape.

This system stores feature information of each components which is generated as a result of design and design parameter in database, so in case of designing draw die with similar features and parameter, this system can be used to extract data needed for manufacturing without same design work.

\subsection{Extraction of Design Information}

The design System composed above, which controls product design process in a view of design administrator, through the concept design step by User-Interface in 2D die shape and connect detail design step by automatic computational 3D component calculation.

Moreover, during the design process this system shows the work-environment that is friendly to the designer using graphics and chart, design error caused by design step blunders. Shown on system-display in the shape of design rule and design method constructed by this system and it can be corrected automatically by system provides tool which can induce design-process referred to design data control module with design-object, design process and User-interface.

And the shape and size of generally designed block is illustrated as a 3D component feature and positioning consider every matter concerned with design and production step in order to connect production step directly.

\section{AN EXAMPLE OF THIS SYSTEM}

\subsection{Development Configuration of this system}

The configuration of system development to construct this system is shown as Figure 3. 


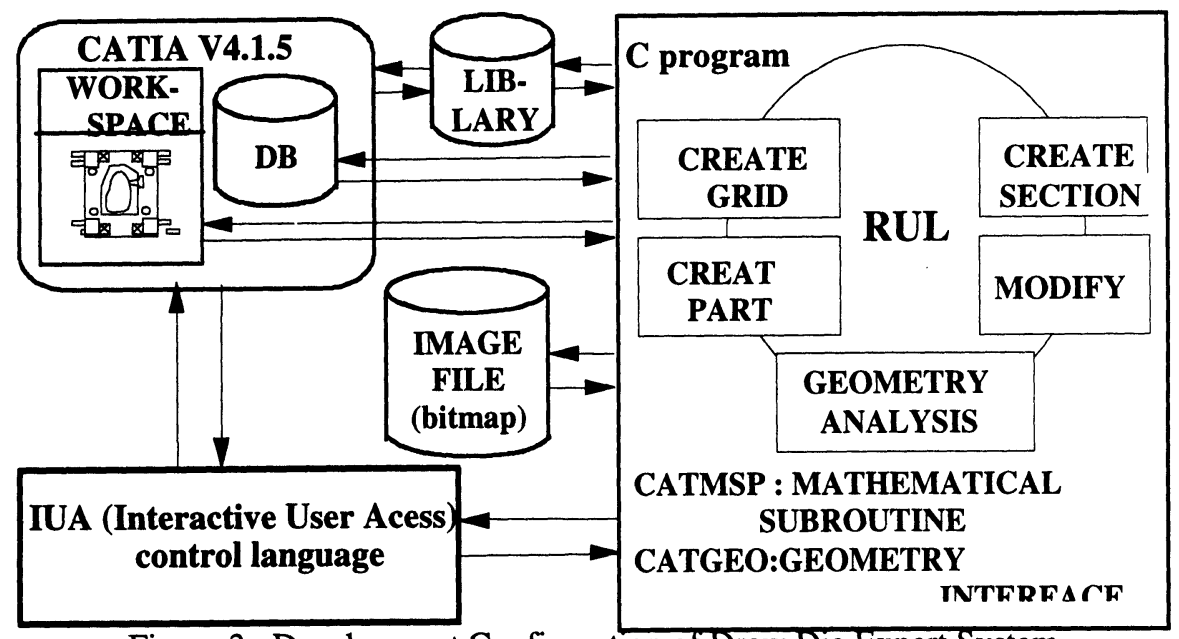

Figure 3. Development Configuration of Draw Die Expert System

The hardware platform of the developed system is IBM RS/6000, the graphic software is CATIA Version 4.1.5, the core modellers are CATGEO and CATMSP of CATIA, and design application programming language is $\mathrm{C}++$ and Motif, we used IUA for GUI also.

\subsection{Case study}

In this section, to prove the effectiveness of the Rule-based system, "Design Expert System for Draw die design of An automobile" which used the solid model of car panel in CATIA environment, is implemented.

But the design process of draw die has a lot of variables according to design condition, and many of its process is not regularised yet. This makes designer to select particular method in the design process sometimes.

The work model, selected to make the system work, is the "Roof Panel" shape of an automobile which is designed and produced really at the H Motor Company. And it used Single action tandem among to Press die design process.

Figures from 4 to 9 are feature windows, showing procedural automated design execution of Draw die.

\section{CONCLUSION}

In the case of die design, The most important and time consuming tasks are reading and understanding the 3-D geometry designed by another designer and decision making for design variables of die. The reason is caused by difficulties in reasoning 3-D geometry from 2-D drawing, and checking on the interference between components. 


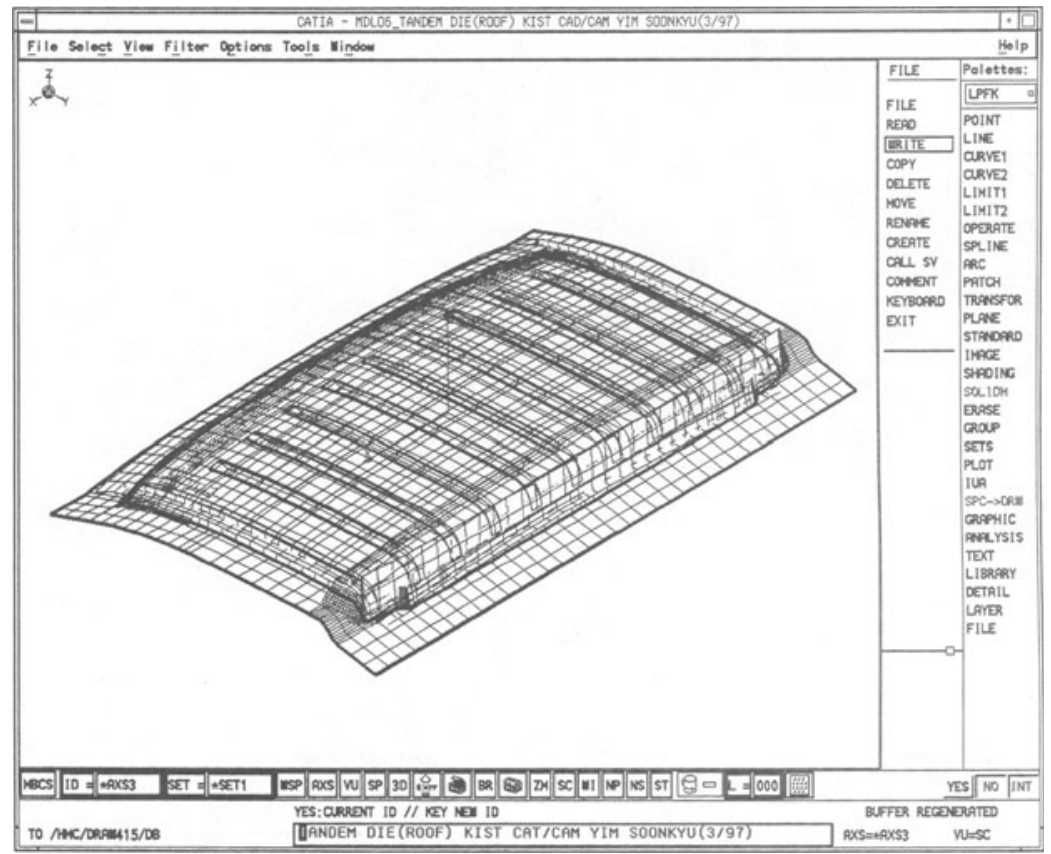

Figure 4. Input of Working Model

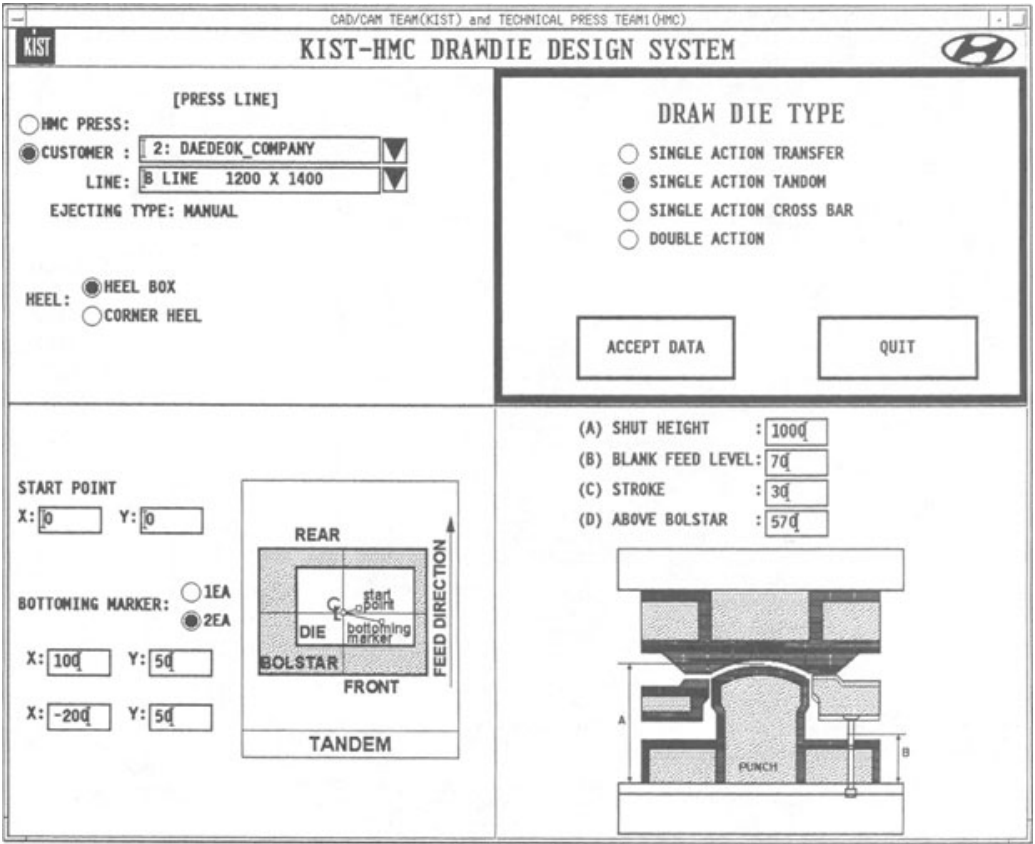

Figure 5. Define of Press Die Creating Condition 


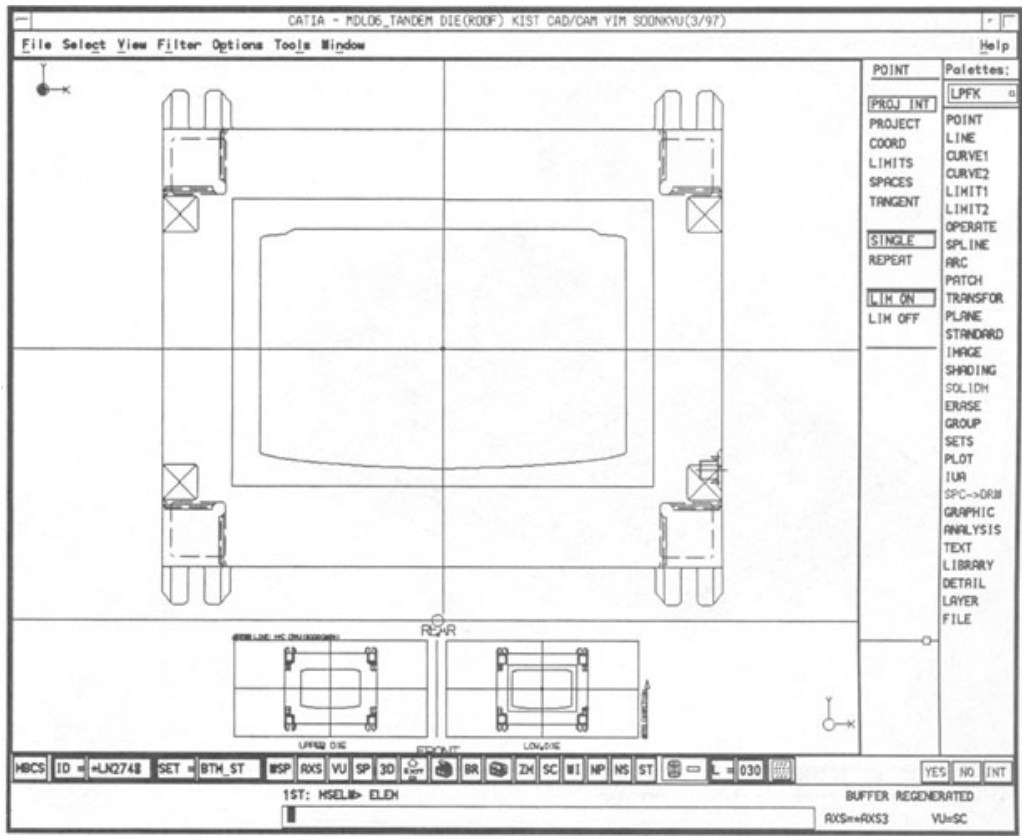

Figure 6. Automatically Decision of Die Size

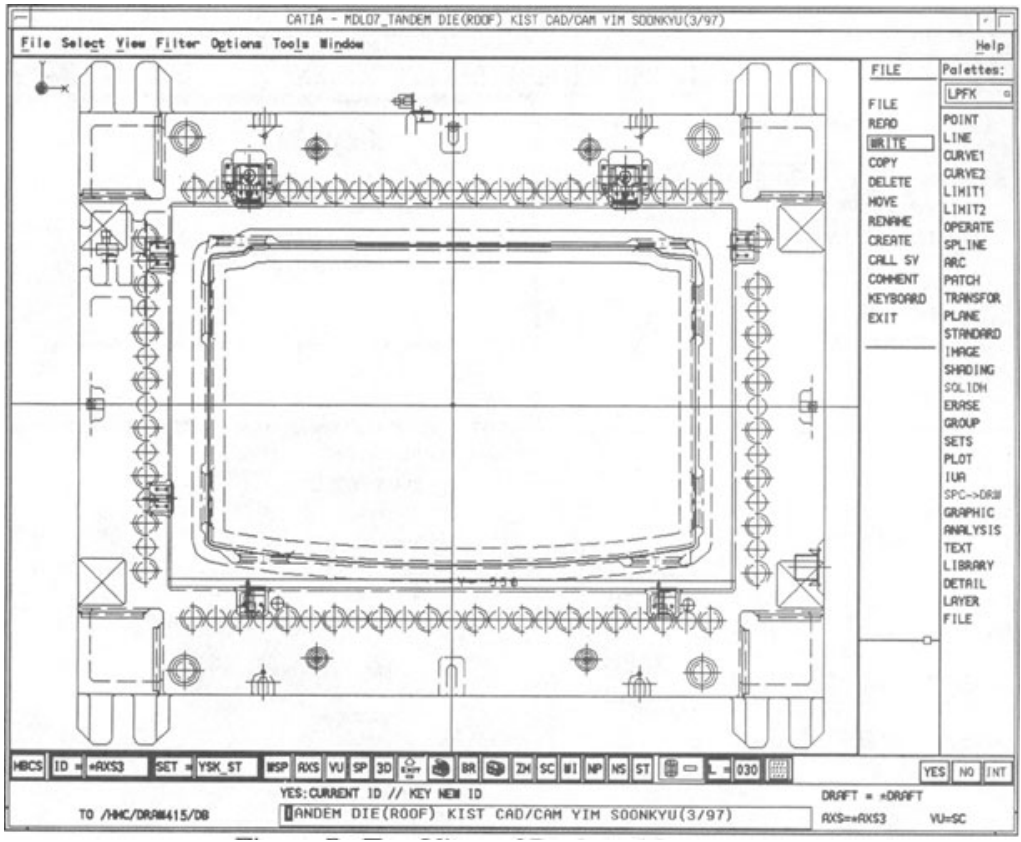

Figure 7. Top View of Designed Lower Die 


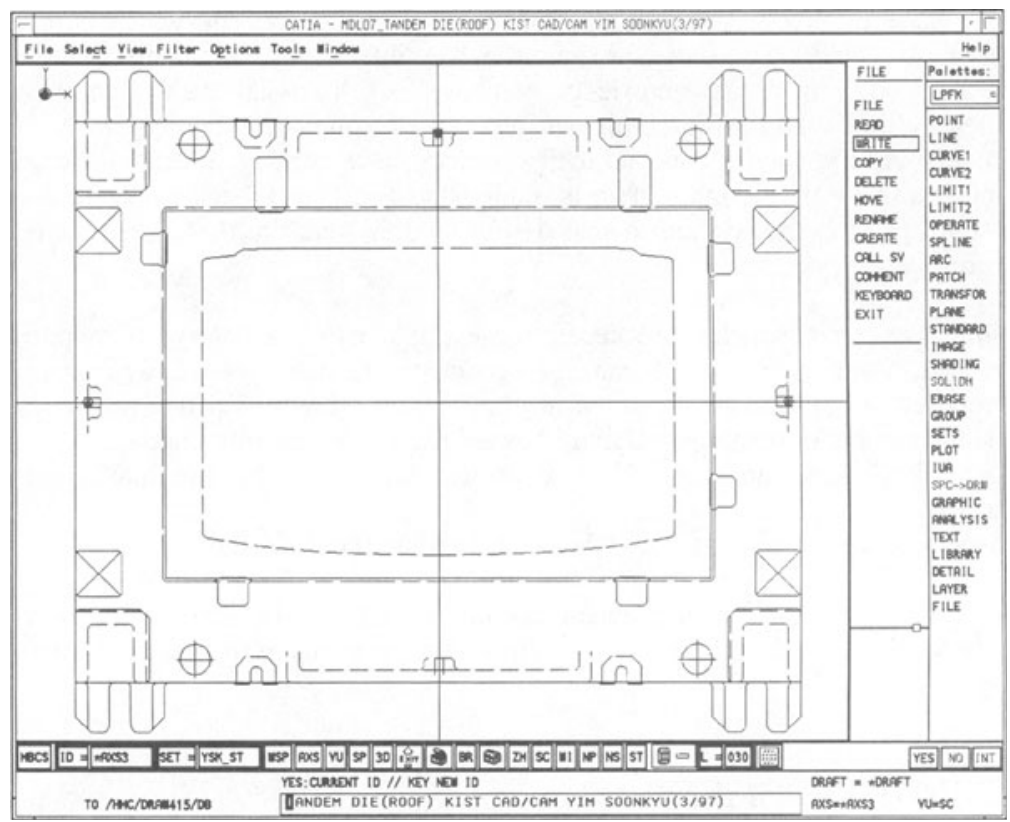

Figure 8. Top View of Designed Upper Die

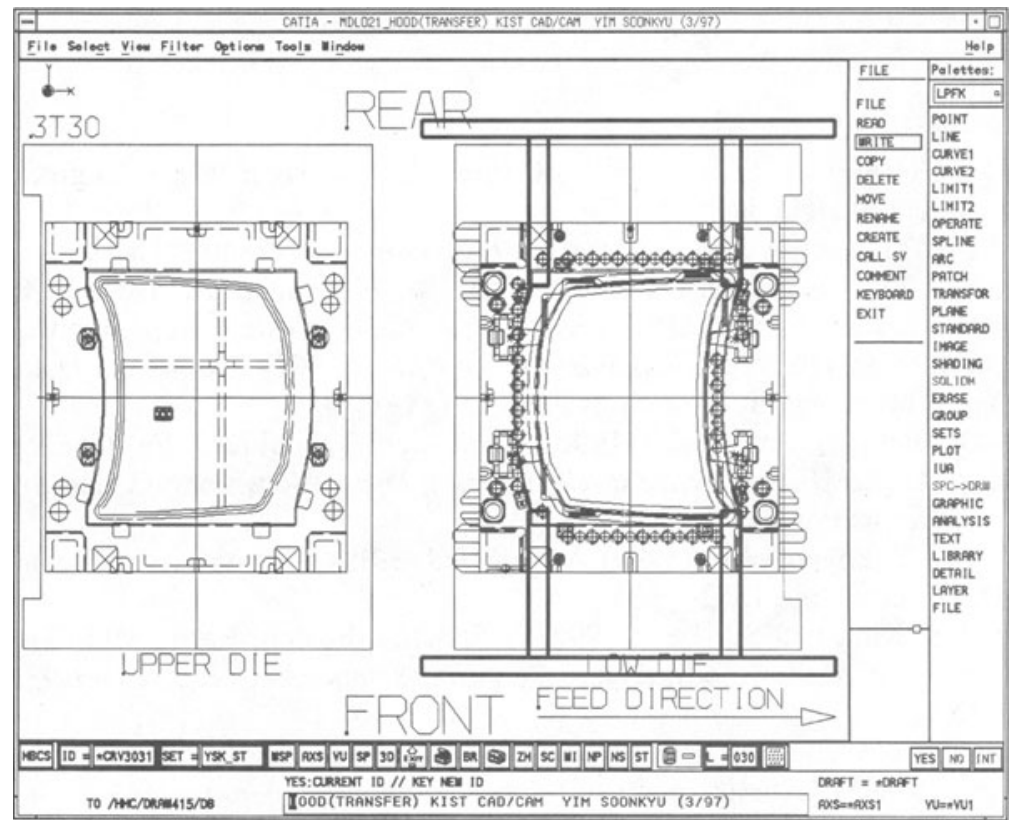

Figure 9. Top View of Designed Draw Die using Single Action Transfer Type 
For solving these problems, We have developed design expert system, which is based on knowledge base and standard data, for draw die. The difficulties are mainly found in the gathering and codifying design knowledge. And we had discussed the design standards, design rules and know-how with the die designers of Korean automobile company for two hundred hours. All the components and their geometry have been modelled by the concept of product data. Now the design system is implemented in H.M.C. and used for draw die design. After applying this system to real design of draw die, the designers evaluate the system as follows:

1) The number of errors, which is proceeded from complexity of geometry can be prevented and reduced. And mathematically managed geometrical data increase design accuracy.

2) The proposed system is easy to practically use, since the codified design process has reduced the number of operation, design knowledge and components standard.

3) Moreover, beginners can design like a design expert by the minimal input with standardised design process.

4) System can reduce design time $70 \%$ when compared with past design.

However, S/W system should be upgraded continuously and a major part of future work will focus on complement of design knowledge, algorithm for decision making and interfacing with analysis system.

\section{ACKNOWLEDGMENT}

The Hyun Dai Motor Co. Ltd has supported this work. We would like to thank the engineers of die division of H.M.C. for their help in gathering design knowledge and standard data.

\section{REFERENCES}

Jeong H.Y. (1996) A Fundamental of Press Die Design, Press Engineering Department of Hyundai Motor Co.

Durkin. (1994) Expert Systems - Design and Development, Prentice Hall Int'l, Inc.

R.D. Coyne, M.A. Rosenman, A.D. Radford, M. Balachandran, and J.S. Gero, (1989) Knowledge-based Design Systems, Addison-Wesley Publishing Co.

Carlo Batini, Stefano Ceri and Shamkant B. Navathe, (1992) Conceptual Database Design, The Benjamin/Cummings Publishing Co.

Serrano D. and Gossard D.C., (1992) Tools and Techniques for Conceptual Design, Artificial Intelligence in Engineering Design (ed. Tong C. and Sriram D.), Academic Press Inc.

Cha J.H. and Yokoyama M., (1995) A Knowledge-Based System for Mechanical CAD, ICED'95, pp. 1382 1386

H.S. Jee, T.S. Kim, and S.J. Lee, (1992) A Standard Feature Based Mold Design System for CAD/CAPP Interface, $7^{\text {th }}$ IFAC Symposium on INCOM'92, pp. 152 157

Pahl G. and Beiz W., (1984) Engineering Design, Springer-Verlag

S. Ohsuga, (1989) Towards Intelligent CAD Systems, Computer Aided Design, Vol. 21 No. 5, pp. 315 337

John Corbett, Mike Dooner, John Meleka 
David G. Ulmann, Larry A. Stauffer and Thomas C. Dietterich, (1987) Toward Expert CAD, Computers in Mechanical Engineering, pp. 56 70

David C. Brown and B. Chandrasekaran, (1983) An Approach to Expert Systems for Mechanical Design, Proceedings, Trend and Application 1983, IEEE Computer Society, pp. 173 180

[CAD Software] (1996) CATIA-Mold and Die Machining Assistant, Dassault System Co.

[CAD Software] (1996) Computer Aided Die Engineering (CADE), Kelton Graphics Co.

[CAD Software] (1994) devis-VAMOS, Debis Systemhaus Industrie 